\title{
A motor facility energy program in a chemical industry
}

\author{
L.F. Mantilla Peñalba, M.A. Rodríguez Pozueta, and R. Diego García \\ Department of Electrical Engineering and Energy \\ E.T.S.I.I., Cantabria University \\ Castros s/n, 39005 Santander (Spain) \\ phone:+34 942 201381, fax:+34 942 201385, e-mail: mantillf@unican.es
}

\begin{abstract}
This report establishes the steps to develop a motor facility energy program, and, therefore, a plant distribution system. The objective is to minimize energy costs, improve the motor feasibility and efficiency, and increase the facility productivity.

A common misconception within industry has been to equate an energy conservation program with the trend of turning off equipment and shutting down processes.

This guide deals with these costs origin and analyzes energy conservation opportunities through motor efficiency and energy usage acquaintance. Energy saving techniques are based on the replacement of standard efficiency motors by high energy efficient units and on correct motor parameters selection. The final objective is to minimize energy usage through production efficiency gains, while achieving the lowest cost and more reliable supplies of fuel and power.
\end{abstract}

\section{Keywords}

Energy management program, reduce energy costs, current plant energy survey, improving efficiency, motor downsizing, energy efficient motors.

\section{Project Outlines}

Developing an energy management program requires the consecution of various stages so that the implantation makes any sense. It is not enough to inspect and collect present situation data and offer immediate solutions to the existing problems, but make a following up of the taken solutions all through the time in order to check the results and correct faults.

This work deals with setting up foundations for accomplishing an energy management program and taking (or not, if everything is working correctly) first measures to the plant energy savings, but in order to develop it completely, it is needed to have a wider view.

\section{Problem Description}

The work works with a group of low-voltage motors from a line process which belong to a chemical industry placed in Cantabria (Columbian Carbon Spain S.A), and involves nameplate powers from $10 \mathrm{CV}$ to $200 \mathrm{CV}$. Data were collected during May and June 2002, therefore, this will be the reference year for further evaluations.

To apply this management program it is required to make a current plant energy survey, so plant electrical distribution system is checked, electric bill is studied and motor electric measures are collected. The following steps are:

1) Conduct energy surveys: an initial plant energy survey that shows where and how energy is being used and/ or wasted.

2) Organize energy data: gathering energy data and understanding its importance.

3) Analyze survey results: setting the energy saving opportunities.

4) Set energy saving goals and constructing an action plan.

5) Develop an organization-wide energy management plan: where engineering changes are implemented.

These points are showed in the following picture:

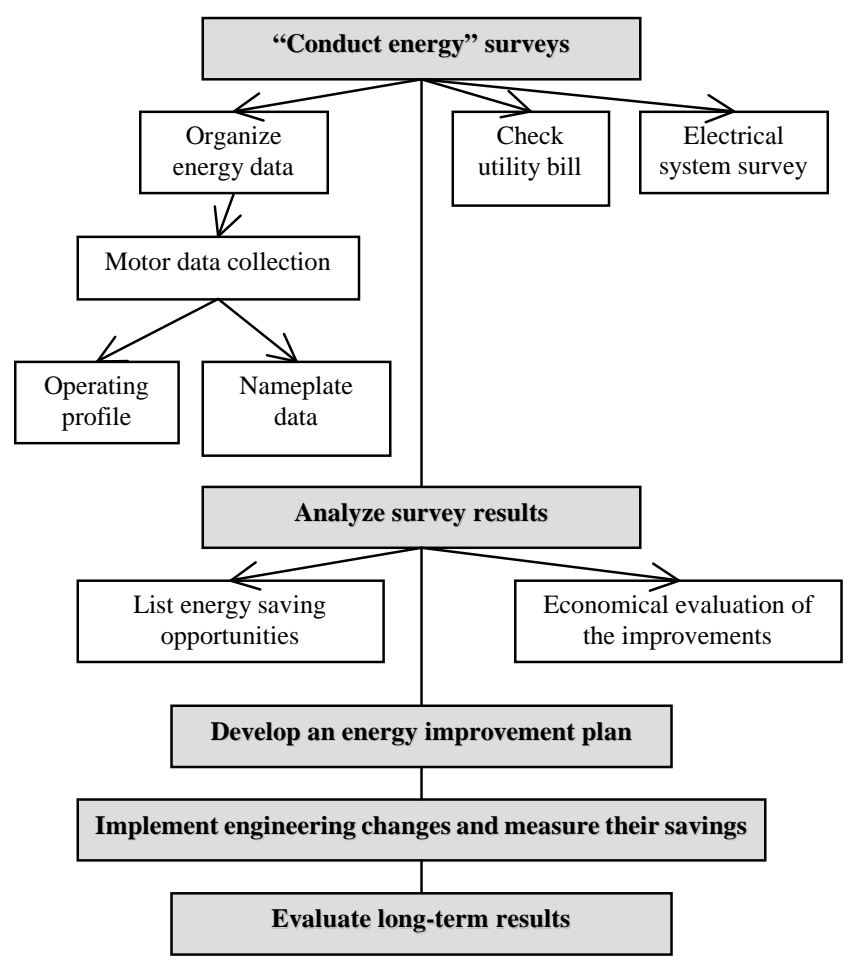

Fig. 1. Steps to develop an energy management program.

\section{The Plant Electrical Distribution System}

In order to count with an appropriate electrical distribution system it is recommended to make secure that it is not a focus of energy losses and unbalances 
which will provoke an efficiency decreasing of the equipments. For that, two important factors must be studied with special interest, which concern the performance and efficiency of the motors; they are the voltage service and frequency system variation and the voltage unbalance of the electrical lines.

Columbian is connected at $55 \mathrm{kV}$ of service voltage, which is later reduced to a couple of transformer substations, inside the plant, at $6,3 \mathrm{kV}$ and $380 \mathrm{~V}$, respectively.

\section{A. Voltage Variation}

The utility is obliged to deliver power to an industrial user's service entrance in the range of $+/-5 \%$ of nominal system voltage. It is also needed to check that the voltage, which reaches at the loads through the electrical plant distribution system, doesn't vary further than $+/-10$ $\%$ of the motor's rated voltage, so that the motor's utilization voltage will be inside this range.

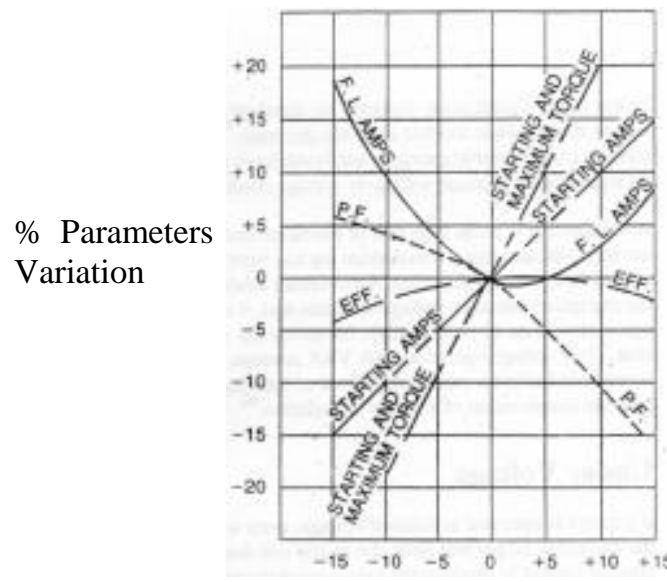

$\%$ Voltage Variation

Fig.2. Motors Parameters Variation with Voltage Supply Variation.

\section{B. Voltage Unbalance}

It is recommended that voltage unbalance doesn't excess $1 \%$. If it does so, the motor must be derated (reduced its power) with a derating factor. An unbalance in phase voltages causes the line currents to be out of balance. The unbalanced currents cause torque pulsations, vibrations, increased mechanical stress on the motor and overheating of one and possibly two of the phase windings. All this damages the motor efficiency, decreasing it.

After making the plant electrical system survey, it is concluded that the installation provides a balanced power because there are no voltage variations. Service and utilization voltage remain in a range of $5 \%$ from nominal system voltage and $10 \%$ from rated motor voltage (342$418 \mathrm{~V})$, respectively.

\section{Actions For The Electrical System Maintenance}

The appropriate maintenance of the electrical system is necessary not only to avoid system losses (which leads to a decreasing of lifetime's equipments, an increasing of costs and a worsening productivity), but to make a more secure plant.

Therefore, it is possible to improve efficiency installation (and, by extension, efficiency motor) through the elimination of common problems such as: 1) Poor contacts. 2) Low power factor. 3) Undersized conductors. 4) Insulation leakage.

\section{Utility Bill}

Through a good knowledge of the utility bill it is possible to account for current energy use, knowing the cost of it, to identify areas with the greatest savings potential, etc.

This work studies the current utility bill, which has special clauses negotiated by Columbian Carbon with the electric service provider, in order to check that actually it is paying less than before, when the bill was suited to the Spanish Electrical Standards. The result is that currently Columbian is paying $24 \%$ less than before (over 34.000 €/month).

\section{Motor Operating Profile}

The main chapter of this work deals with the energetic situation of a group of electric motors and with the development of an improvement planning to get their efficiency increased and, therefore, to achieve energy savings.

The selected motors are 17 with a nominal power range from $7,5 \mathrm{~kW}$ to $160 \mathrm{~kW}$. The field measurements (input power, speed) were made "in situ" during May and June 2.002. They revealed that in most cases motors worked under their capabilities.

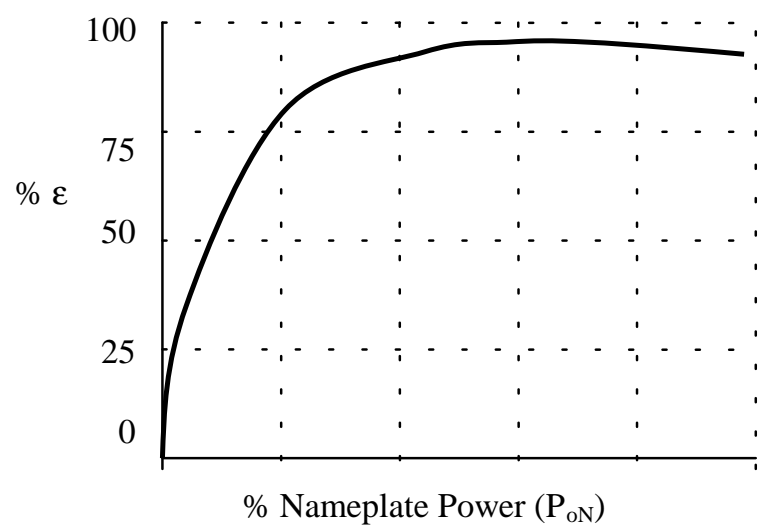

Fig. 3. Curve Efficiency vs. Load.

A motor that works at $70-80 \%$ of his full load power, keeps its parameters (efficiency, power factor, etc) near to the optimal values. Motor parameters are normally given by the manufacturer at full-load conditions (nominal conditions), but this situation doesn't have to be the real one. Since these parameters vary with the load, it 
is necessary to know their real operating points in plant. Here, it appears some difficulties because of the nonlinear relationship between efficiency, amperes, etc, and load. This makes that their resolution is not immediate.

It is interesting to remark the importance of making an accurate motor load and efficiency calculation (at load point). These are based on input data (and not on output data, as their definitions set) and, therefore, are estimation techniques. So, the study can be done by input power and current measurements and speed measures from motors, establishing the three estimation load techniques. Input voltage, current and power data were collected "in situ" for each sort of made product in the line. The load factor is defined below, which is calculated from the input values (power, current, etc), $\mathrm{C}_{\mathrm{in}}$, distinguishing it from the calculated one by output parameters, $\mathrm{C}_{\mathrm{o}}$.

$$
\begin{aligned}
& C_{\text {in }}=\frac{P_{\text {in }}}{P_{i n N}} \times 100 \\
& C_{o}=\frac{P_{o}}{P_{o N}} \times 100=\frac{P_{i n} \cdot \varepsilon}{P_{i n N} \cdot \varepsilon_{N}} \times 100
\end{aligned}
$$

If the motor is $50 \%$ under loaded, the rate between input current and motor load is not linear, so that the real shaft power calculations are not immediate. Also, there's a non-direct dependence between load factor and efficiency, since a motor the more loaded it is, the greater losses it has, although these losses do not increase in the same way for different load conditions.

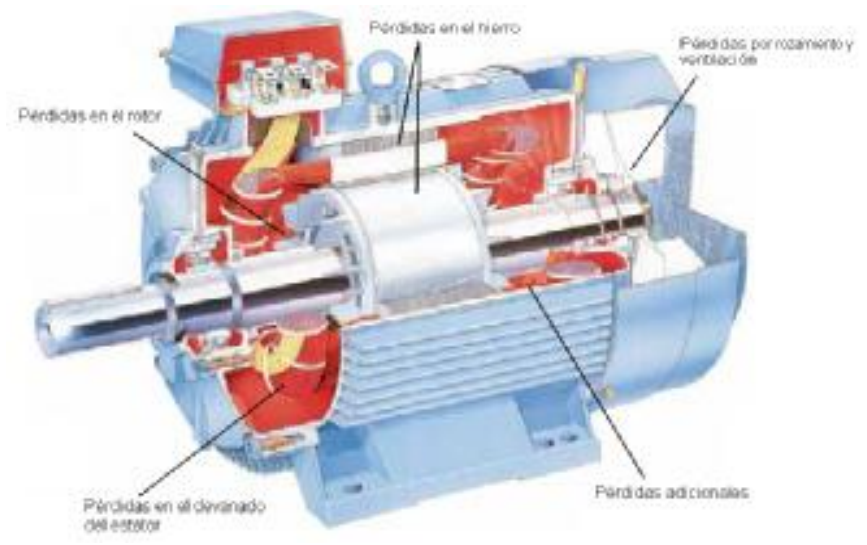

Fig.4. Motor Losses.

Several reports and European and American Standards have helped to develop a software that calculates the motor load factor and efficiency (at load point) for motors that are $50 \%$ over loaded. This software estimates first the losses upon real work conditions for each motor and then obtains the efficiency (indirect method). For the rest of the motors efficiencies are calculated by looking up manufacturer's tables and using linear interpolation method at different performance conditions, "real" efficiency is calculated. Finally, an operating profile is obtained for each motor with the help of collected data like_annual operating hours, energy cost $(€ / \mathrm{kWh})$, input and output power (load factor and efficiency at real conditions having been obtained).

The next picture shows annual operating profiles of two motors belonging line process, drawing with the help of collected data; input power for each load condition (depending on what sort of product is been made), output power (after knowing efficiency and load factor at load point) and nominal power, thus giving a first view of how is the motor being used in relation to its capabilities:

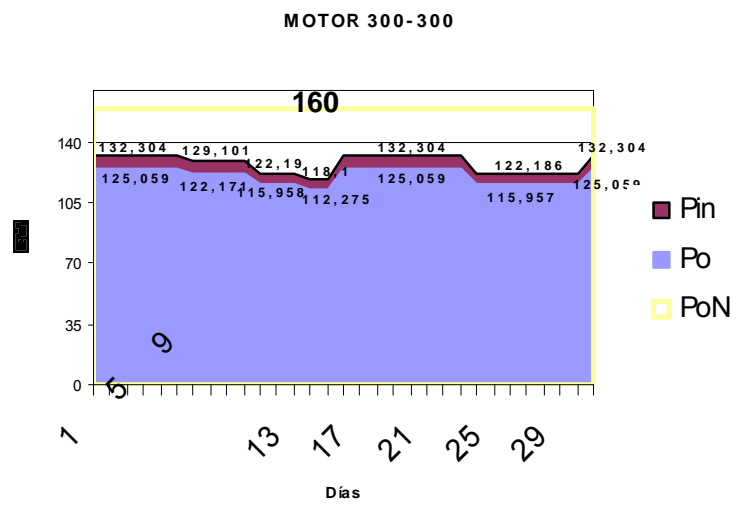

Fig. 5. Operating profile of a high power motor (160 $\mathrm{kW}$ ), working at nominal conditions.

\section{MOTOR 300-301}

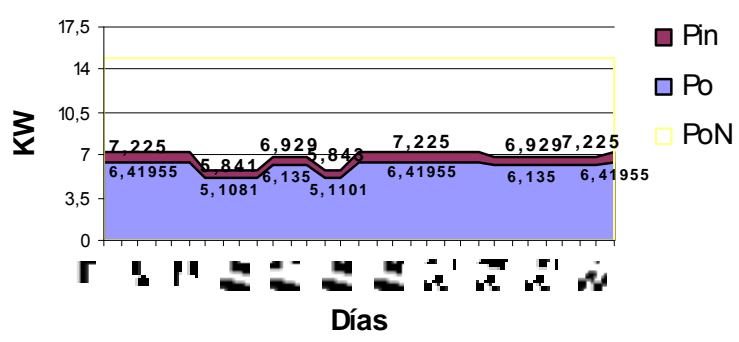

Fig. 6. Operating profile of a low power motor (15 $\mathrm{kW}$ ), working far of the nominal conditions.

In both pictures it is showed the different performance conditions of the two motors. The first one is operating near the conditions so that it was designated and the second one is rather below its capabilities. Energy saving opportunities seems to be greater for the smaller one due to its efficiency loss as the consequence of working far below $50 \%$ rated power and not to suit properly to load requirements; but since the $160 \mathrm{~kW}$ motor needs a large quantity of energy, a little improvement in its operating efficiency can mean a greater energy saving. Therefore, it is not only necessary to know how much the efficiency can get better and its money savings, but also if it is able to make profitable the required investment.

Once the energy demands for all 17 motors are obtained it is confirmed that most of them operate fairly below 
their capabilities. That is the reason why the solutions offered to improve the motor efficiency and, consequently, to decrease energy usage and costs, are being focused in that way, that is to say:

1) Alternative 1: increase efficiency by suiting the nameplate power of the motor to the real output power required by the driving-equipment.

2) Alternative 2: increase by replacing current motors by energy efficient motors.

3) Alternative 3: increase efficiency by mixing both alternatives.

TABLE I. - Efficiency Increase Depending On The Alternatives.

\begin{tabular}{|c|c|c|c|c|}
\hline \multirow{2}{*}{ MOTOR } & $\varepsilon_{\mathrm{m} \text { present }}$ & Alternatv.1 & Alternatv.2 & Alternatv.3 \\
\cline { 3 - 5 } & $(\%)$ & $\varepsilon_{\mathrm{m} \text { new }}(\%)$ & $\varepsilon_{\mathrm{m} \text { new }}(\%)$ & $\varepsilon_{\mathrm{m} \text { new }}(\%)$ \\
\hline $300-300$ & 94,728 & 94,728 & 96,328 & 96,328 \\
\hline $300-301$ & 88,228 & 90,066 & 90,027 & 90,953 \\
\hline $300-302$ & 87,408 & 89,000 & 89,073 & 90,200 \\
\hline $300-303$ & 91,869 & 92,398 & 92,870 & 93,988 \\
\hline $300-304$ & 83,704 & 84,374 & 87,683 & 87,574 \\
\hline $300-305$ & 90,772 & 92,039 & 91,372 & 93,158 \\
\hline $300-306$ & 92,072 & 92,778 & 93,174 & 93,840 \\
\hline $300-307$ & 92,846 & 93,347 & 94,061 & 94,544 \\
\hline $300-308$ & 89,207 & 91,547 & 89,807 & 92,512 \\
\hline $300-309$ & 92,533 & 93,257 & 94,080 & 94,274 \\
\hline $300-310$ & 91,194 & 92,777 & 92,594 & 93,555 \\
\hline $300-311$ & 92,112 & 92,112 & 93,116 & 93,116 \\
\hline $300-316$ & 88,511 & 90,787 & 89,862 & 92,568 \\
\hline $300-317$ & 90,800 & 93,126 & 91,700 & 94,409 \\
\hline $300-318$ & 53,00 & 76,867 & - & 84,754 \\
\hline $300-323$ & 90,286 & 90,286 & 91,152 & 91,152 \\
\hline
\end{tabular}

All the three alternatives increase, more or less, the average efficiency that, presently plant motors have. As it is already said, now it is necessary to study if the reached savings are enough to make profitable the investments.

\section{Savings Analysis}

Finally, an economical analysis of the improvements reached and its budget end this report, justifying economically the improvements provided to get energy savings. Starting from the three efficiency improvement alternatives analyzed, four different solutions are proposed:

1) To replace four motors by other energy efficient units.

2) To redesign the motor distribution to achieve energy savings by suiting the motor size to the power required.

3) To replace three motors by energy efficient units and redistribute the rest of the motors.

4) To replace two motors by energy efficient units and redistribute the rest of the motors.

The first study made was the simple payback analysis and when motors with less than 2 or 3 years were extracted, it is obtained the savings by the suitable alternative (alternative 3 ), the alternative 1 improvement and other intermediate solutions. Alternative 1 improvement consists in obtaining savings by suiting the rated power but not doing any investment, that is to say, using present motors belonging to the line process, and redesigning them in the appropriate way.

TABLE II. - Solutions

\begin{tabular}{|c|c|c|}
\hline Solution & $\begin{array}{c}\text { Accumulate } \\
\text { Saving (€) }\end{array}$ & $\begin{array}{c}\text { Annual } \\
\text { Saving (€) }\end{array}$ \\
\hline 1 & 815,61 & 956,49 \\
\hline 2 & $4.194,23$ & $1.198,35$ \\
\hline 3 & $2.883,85$ & $1.490,82$ \\
\hline 4 & $3.912,95$ & $1.329,05$ \\
\hline
\end{tabular}

The optimal solution is the fourth and its annual saving adds up to $1.329,05 €$, once the investment is paid off. In addition, a feasibility analysis is made, supported by economical parameters (VAN and TIR).

TABLE III. - Budget

\begin{tabular}{|c|c|c|c|}
\hline Unit & $\begin{array}{c}\text { Price } \\
\text { Cost }(€)\end{array}$ & $\begin{array}{c}\text { Installation } \\
\text { Cost }(€)\end{array}$ & $\begin{array}{c}\text { Total } \\
\text { Cost }(€)\end{array}$ \\
\hline Motor 300-316 & 688,2 & - & 688,2 \\
\hline Motor 300-318 & 140,16 & - & 140,16 \\
\hline TOTAL & & & 828,36 \\
\hline
\end{tabular}

\section{Conclusions}

This work pretends to give the main points to establish an energy management program in Columbian Carbon Spain S.A., and by extension, to any factory.

In this study, the number of the studied motors is not very large so the savings are not too; but this fact does not lessen it importance, although this kind of management program develops its real advantages when it is applied to the whole motor plant during a long time. Therefore, this project would have more repercussion if it were involved in a greater one.

The suggestions are "a first solution" to the present plant situation, but its changes must be followed and analyzed through the time; this will determine the validity and extent of the improvements.

\section{References}

[1] McCoy, G.A. and Douglass, J.G. "Energy efficient electric motor selection handbook". Washington State Energy Office. Olympia, Washington, USA.

[2] McCoy, G.A. "Energy management for motor driven systems". Office of Industrial Technologies, USA.

[3] Nailen, Richard L. “Managing Motors". P.E. Second edition.

[4] EASA, "Understanding energy efficient motors". Reliable Solutions Today.

[5] Viego Felipe, Percy R. and Cardenas Martínes, Ada U. "Un proyecto para el ahorro de energía con la 
instalación de motores asincrónicos de alta eficiencia". Cienfuegos University, Cuba. Publisher on www.energia.com.

[6] Wilke, K. and Ikuenobe, T. "Guidelines for implementing an energy-efficient motor retrofit program". Presented at 10th World Energy Engineering Congress, sponsored by Association of Energy Engineers, Atlanta, Ga.

[7] Lobodovski, K.K, Ganeriwal R. and Gupta, A, PG\&E Co. "Field measurements and determination of electric motor efficiency" extracted from "Energy Engineering", Vol. 86, No.3, 1.989.
[8] Montgomery D. "Testing rewinds to avoid motor efficiency degradation". Published in 1.985, 8th World Energy Engineering Congress, published by the Association of Energy Engineers.

[9] Consortium for Energy Efficiency. "Motor planning kit". 